\title{
Organic calcium silicate hydrate hybrids: a new approach to cement based nanocomposites $\dagger$
}

\author{
Jérôme Minet, ${ }^{a}$ Sébastien Abramson, ${ }^{b}$ Bruno Bresson, ${ }^{c}$ Alexandre Franceschini, ${ }^{a}$ Henri Van Damme ${ }^{a}$ and \\ Nicolas Lequeux*a
}

\author{
Received 9th November 2005, Accepted 6th January 2006 \\ First published as an Advance Article on the web 23rd January 2006 \\ DOI: $10.1039 / b 515947 d$
}

\begin{abstract}
Novel hybrid organic-inorganic calcium silicate hydrate $(\mathrm{C}-\mathrm{S}-\mathrm{H})$ materials have been synthesized via a sol-gel process. The materials are obtained by precipitation in alkali media of a mixture of trialkoxysilane (ethyltriethoxysilane, $n$-butyltrimethoxysilane or 3-aminopropyltriethoxysilane) and tetraethoxysilane diluted in $\mathrm{CaCl}_{2}$ ethanol-water solution. XRD experiments show an increase of the basal distance of $\mathrm{C}-\mathrm{S}-\mathrm{H}$ with the content of trialkoxysilane suggesting the incorporation of organic moieties in the interlayer. ${ }^{29} \mathrm{Si} \mathrm{NMR}$ data show that the organic species do not disrupt the inorganic framework of C-S-H. 2D ${ }^{1} \mathrm{H}-{ }^{29} \mathrm{Si}$ HETCOR NMR experiments confirm that trialkoxysilanes such as ethyl- or aminopropyl-silane are incorporated in the silicate chains of the $\mathrm{C}-\mathrm{S}-\mathrm{H}$ structure. In the case of highly hydrophobic trialkoxysilanes such as $n$-butyltrimethoxysilane, the results suggest that a separation occurs between silicates and trialkoxysilanes, leading to a mixture of inorganic $\mathrm{C}-\mathrm{S}-\mathrm{H}$ on one hand and $100 \%$ organosilane calcium hybrid phase on the other hand.
\end{abstract}

\section{Introduction}

Improvements in mechanical properties of hardened cements, mortars and concretes, such as toughness and strength, are a permanent challenge which could be successfully achieved by the incorporation of polymers as observed in hard biological materials. For example, cement-polymer composites with a flexural strength 10 times greater than that of ordinary cement pastes have been obtained by mixing high-alumina cements with water containing a water soluble polymer such as polyvinyl alcohol. ${ }^{1,2}$ However, only a limited increase in fracture resistance has been achieved. This is probably due to bad dispersion and adhesive properties control of the organic component into the inorganic matrix which is thought to be the key to a biological material's fracture toughness. ${ }^{3,4}$

In ordinary cement, the major phase responsible for cohesion is a calcium silicate hydrate labelled " $\mathrm{C}-\mathrm{S}-\mathrm{H}$ ". $\mathrm{C}-\mathrm{S}-\mathrm{H}$ is thought to form nano-sized layered crystals with a structure related to tobermorite, ${ }^{5}$ a natural mineral analogue. ${ }^{6}$ The structure of the tobermorite layer is based on a distorted central $\mathrm{Ca}-\mathrm{O}$ sheet flanked on each side by silicate "dreierketten" chains, i.e. silicate chains with a period of three

${ }^{a}$ Laboratoire de Physicochimie des Polymères et Milieux Dispersés, UMR7615-CNRS, Ecole Supérieure de Physique et de Chimie Industrielles, 10 rue Vauquelin, 75005 Paris, France.

E-mail: nicolas.lequeux@espci.fr; Fax: +33 (0) 1407946 40; Tel: +33 (0) 140794643

${ }^{b}$ Laboratoire Colloïdes et Matériaux Divisés, UMR7612-CNRS, Ecole Supérieure de Physique et de Chimie Industrielles, 10 rue Vauquelin, 75005 Paris, France

${ }^{c}$ Laboratoire de Physique Quantique, UPR5-CNRS, Ecole Supérieure de Physique et de Chimie Industrielles, 10 rue Vauquelin, 75005 Paris, France

$\uparrow$ Electronic supplementary information (ESI) available: XRD patterns; plot of $d_{001}$ vs. n-octyltrialkoxysilane fraction; ${ }^{29} \mathrm{Si}$ and ${ }^{13} \mathrm{C} \mathrm{CP}$ MAS NMR spectra. See DOI: 10.1039/b515947d tetrahedra. The interlayer space contains water molecules and additional $\mathrm{Ca}^{2+}$ cations which balance the negative charge of the main layer. Compared to tobermorite, C-S-H can accommodate a substantial concentration of structural defects such as the omission of tetrahedra and a variable amount of calcium ions in the interlayer. ${ }^{7,8}$ Inconsistent results have been reported about the intercalation of polymers in $\mathrm{C}-\mathrm{S}-\mathrm{H}$. Matsuyama and Young ${ }^{9-11}$ claimed that a broad range of anionic, cationic and neutral polymers can be intercalated in the $\mathrm{C}-\mathrm{S}-\mathrm{H}$ layers depending on the $\mathrm{Ca} / \mathrm{Si}$ ratio of the solid. This is in disagreement with further reports in which evidence of interlayer intercalation of previously used polymers was not found. ${ }^{12,13}$

Herein, we propose an alternative method to incorporate small organic groups inside the interlayer. These organic groups are covalently linked to the inorganic part of $\mathrm{C}-\mathrm{S}-\mathrm{H}$ via $\mathrm{Si}-\mathrm{C}$ bonds. Such hybrids are obtained by co-precipitation of $\mathrm{R}^{\prime} \mathrm{Si}(\mathrm{OR})_{3}$ organotrialkoxysilane and $\mathrm{Si}\left(\mathrm{OC}_{2} \mathrm{H}_{5}\right)_{4}$ tetraethoxysilane (TEOS) mixtures in the presence of calcium salt in aqueous/ethanolic basic solution. Using this sample procedure, we were able to synthesize organic-calcium silicate layered hybrids with a large range of composition. The present work demonstrates that $\mathrm{C}-\mathrm{S}-\mathrm{H}$ can accommodate small sized organic groups in the interlayer space, directly linked to silicate chains.

\section{Experimental}

Calcium silicate hydrate-organic hybrid materials were prepared by the hydrolysis of a mixture of $5 \times 10^{-3} \mathrm{~mol}$ of trialkoxysilane and tetraethoxysilane (TEOS) in a solution containing $0.46 \mathrm{~g}$ of $\mathrm{CaCl}_{2}$ dissolved in $0.1 \mathrm{M} \mathrm{HCl}\left(1.35 \mathrm{~cm}^{3}\right)$ and ethanol $\left(6.9 \mathrm{~cm}^{3}\right)$ for $1 \mathrm{~h} .1 \mathrm{~cm}^{3}$ of aqueous sodium hydroxide solution (4 M) was then added under vigorous 
agitation. The base addition resulted in a rapid precipitation. The precipitate was aged under agitation for $12 \mathrm{~h}$ at room temperature and then washed twice by centrifugation with deionized water. Finally, the solid was dried under vacuum for 1 day. The trialkoxysilanes used were ethyltriethoxysilane $\left(\mathrm{C}_{2} \mathrm{H}_{5} \mathrm{Si}\left(\mathrm{OC}_{2} \mathrm{H}_{5}\right)_{3}\right)$, n-butyltrimethoxysilane $\left(\mathrm{C}_{4} \mathrm{H}_{9} \mathrm{Si}\left(\mathrm{OCH}_{3}\right)_{3}\right)$, or 3-aminopropyltriethoxysilane $\left(\mathrm{H}_{2} \mathrm{~N}\left(\mathrm{CH}_{2}\right)_{3} \mathrm{Si}\left(\mathrm{OC}_{2} \mathrm{H}_{5}\right)_{3}\right)$. In all samples, the $\mathrm{Ca} / \mathrm{Si}$ molar ratio was fixed to 0.83 which is the typical ratio value found in well-crystallized calcium silicate hydrate $(\mathrm{C}-\mathrm{S}-\mathrm{H}){ }^{6}$ The percentage of trialkoxysilane relative to the total source of silicon was varied from 0 to $100 \%$. Elemental analysis of the synthesized hybrid equilibrium solutions showed that the great majority of silicon and calcium ions were incorporated into the solid phase.

X-Ray diffraction patterns were recorded using a powder diffraction set up in transmission mode ${ }^{14}$ (Debye-Scherrer geometry) with $\mathrm{Cu} \mathrm{K} \alpha_{1}$ radiation $(30 \mathrm{~mA} \times 30 \mathrm{kV})$ in $0.5 \mathrm{~mm}$ Lindemann capillaries for $5 \mathrm{~h}$. NMR experiments were performed with a Bruker ASX 500 spectrometer. Crosspolarization magic angle spinning (CP-MAS) ${ }^{29} \mathrm{Si}$ and $2 \mathrm{D}$ ${ }^{1} \mathrm{H}_{-}{ }^{29} \mathrm{Si}$ HETeronuclear chemical shift CORrelation (HETCOR) spectra were recorded using a MAS frequency of $5 \mathrm{kHz}$, a contact time of $2 \mathrm{~ms}$ and a recycle delay of $5 \mathrm{~s} .{ }^{1} \mathrm{H}$ and ${ }^{29} \mathrm{Si}$ chemical shifts were referenced using adamantane and TMS respectively.

\section{Results and discussion}

Organic-calcium silicate hybrids were synthesized by varying the starting fraction of trialkoxysilane from 0 to $100 \%$ with a fixed $\mathrm{Ca} / \mathrm{Si}$ ratio. The pure inorganic material $(0 \%$ of trialkoxysilane, $100 \%$ of TEOS) XRD pattern is typical of a pattern of relatively well crystallized $\mathrm{C}-\mathrm{S}-\mathrm{H}^{6}$ (Fig. 1). The pattern shows broad in-plane peaks at $0.304,0.280,0.182$, and

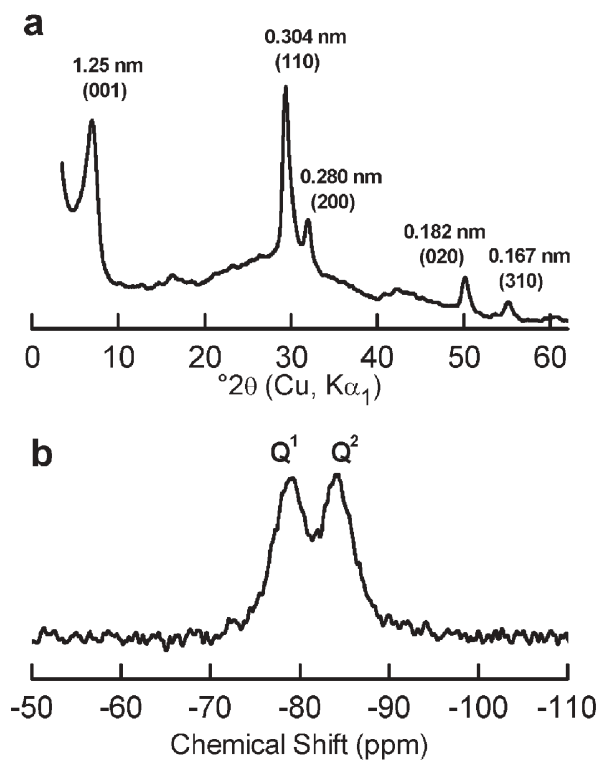

Fig. 1 XRD diagram (a) and ${ }^{29} \mathrm{Si}$ CP-MAS NMR spectrum (b) of C-S-H (without trialkoxysilane). XRD peaks have been indexed in an orthorhombic cell with $a=0.560 \mathrm{~nm}, b=0.364 \mathrm{~nm}$, and $c=1.25 \mathrm{~nm}$ as suggested by Taylor. ${ }^{6}$
$0.167 \mathrm{~nm}$ together with a basal reflection at $1.25 \mathrm{~nm}$. Resonances at -79 and $-84 \mathrm{ppm}$ are observed by ${ }^{29} \mathrm{Si}$ CP-MAS and they are assigned to end-chain tetrahedra $\mathrm{Q}^{1}$ and middle-chain tetrahedra $\mathrm{Q}^{2}$ species respectively ${ }^{15}$ (Fig. 1).

At the opposite end of the series, the $100 \%$ organic-calcium silicate hybrids (100\% of trialkoxysilane, $0 \%$ of TEOS) are characteristic of lamellar phases with a varying basal distance depending on the organic moiety size. In a previous study, we have proposed a structural model for these materials. ${ }^{16}$ In the case of n-alkyltrialkoxysilanes used as starting precursors, XRD data are consistent with the presence of a bilayer alkyl chain arrangement between inorganic sheets. As observed in Fig. 2, the basal distance increases from 1.35 to $1.70 \mathrm{~nm}$ in lamellar hybrids made from ethyltriethoxysilane and n-butyltrimethoxysilane used as starting precursors respectively. The substitution of $n$-butyl by aminopropyl moieties linked to silane, which are approximately equal in size, leads to a similar basal distance value. In 100\% organic-calcium silicate hybrid materials, broad in-plane diffraction peaks at 0.30 and $0.178 \mathrm{~nm}$ are always present. These peaks are consistent with those of a smectite-like layer arrangement, suggesting that the hybrid's inorganic part is characterized by silicon atoms condensed onto each side of a single $\mathrm{Ca}(\mathrm{OH})_{2}$ brucite-like layer instead of the very distorted $\mathrm{Ca}-\mathrm{O}$ layer of $\mathrm{C}-\mathrm{S}-\mathrm{H} .{ }^{16}$

Starting from pure inorganic end-series $(\mathrm{C}-\mathrm{S}-\mathrm{H})$ and substituting a fraction of TEOS by trialkoxysilane, we observed a basal distance increase and progressive changes of the C-S-H non-basal peaks toward ill-defined peaks of the

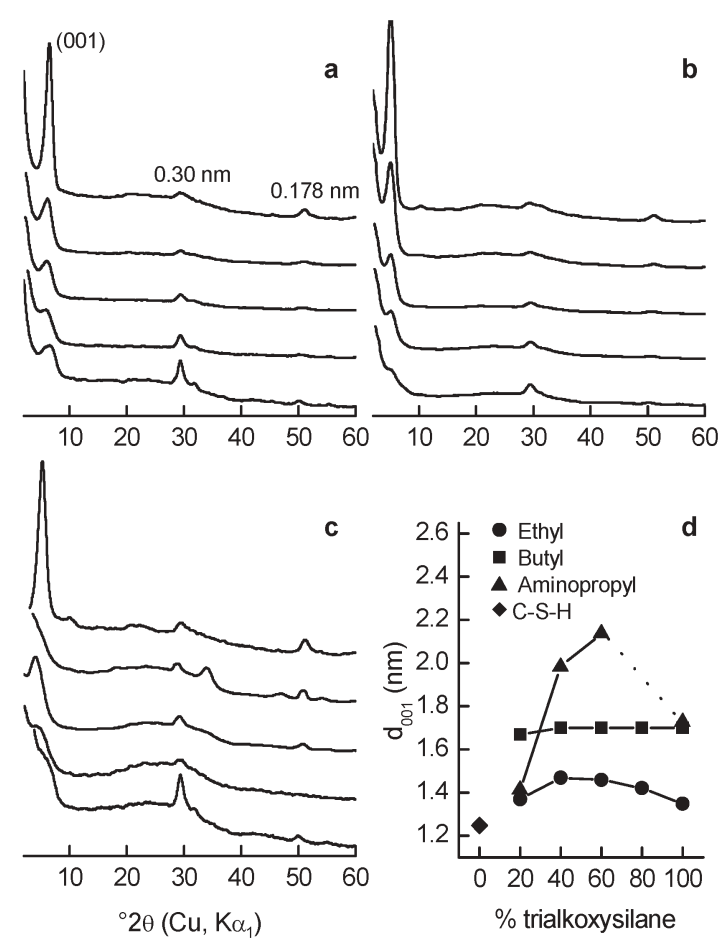

Fig. 2 XRD diagrams of (a) ethyl, (b) $n$-butyl, and (c) aminopropyl calcium silicate hybrid series. In each figure, the fraction of trialkoxysilane (in $\mathrm{mol} \%$ ) varies from 20 to $100 \%$ by $20 \%$ steps from the bottom to the top. (d) Basal distance variation $\left(d_{001}\right)$ with trialkoxysilane percentage for ethyl, butyl, and aminopropyl organic moieties. 
$100 \%$ organic calcium silicate hybrids (Fig. 2). In the case of the $\mathrm{R}^{\prime}=$ ethyl series, $d_{001}$ increased up to $1.47 \mathrm{~nm}$ for samples containing $40 \%$ ethylsilane precursor and then decreased to $1.35 \mathrm{~nm}$ for the $100 \%$ substituted material. This trend is highly pronounced in the case of the aminopropyl series. In this series, the basal distance reached a value of $2.14 \mathrm{~nm}$ for $60 \%$ substitution compared to $1.73 \mathrm{~nm}$ for the $100 \%$ substituted sample. In the $80 \%$ substituted sample, the layered arrangement was lost. The non-monotonic variation of $d_{001}$ with the percentage of trialkoxysilane for both series is not clear but seems inconsistent with a phase separation between $\mathrm{C}-\mathrm{S}-\mathrm{H}$ and $100 \%$ organic calcium silicate.

The XRD patterns of the $n$-butyl series (and longer $n$-alkyl series, see ESI $\uparrow$ ) are very different from the previous ones. As soon as the TEOS substitution became higher than $20 \%$, the basal distance reached a constant value equal to that of the completely substituted sample. Moreover, the intensity of the basal peak increased with the substitution level. This suggests that for this series, a phase separation between the $100 \%$ organic calcium silicate phase and $\mathrm{C}-\mathrm{S}-\mathrm{H}$ probably occurs as soon as TEOS is substituted by $n$-butyltrialkoxysilane.

Additional structural information on the hybrid has been obtained by ${ }^{29} \mathrm{Si}$ NMR experiments (Fig. 3). As TEOS is progressively substituted by an organotrialkoxysilane, resonances in the chemical shift range of trifunctional silicon ${ }^{17,18}$ $\left(\mathrm{T}^{n}=\mathrm{RSi}\left(\mathrm{OR}^{\prime}\right)_{3-n}(\mathrm{OSi})_{n}\right)$ are observed at the expense of $\mathrm{Q}$ resonances. In substituted samples, the $\mathrm{SiO}_{4}$ tetrahedra remain in the form of chains $\left(Q^{1}\right.$ plus $Q^{2}$ environment) as in
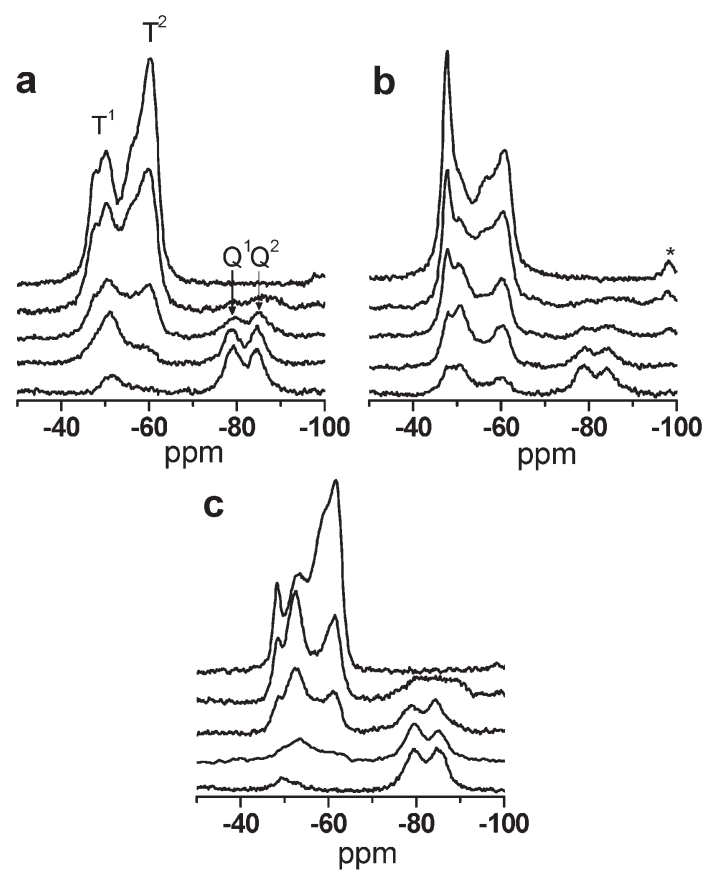

Fig. $3{ }^{29} \mathrm{Si}$ CP-MAS NMR spectra of (a) ethyl, (b) $n$-butyl, and (c) aminopropyl calcium silicate series. In each figure, the fraction of trialkoxysilane (in $\mathrm{mol} \%$ ) varies from 20 to $100 \%$ by $20 \%$ steps from the bottom to the top. Due to non-quantitative results obtained by cross-polarization, the T/Q ratio does not actually match the initial organotriethoxysilane/TEOS molar ratio (* denotes spinning sidebands). pure $\mathrm{C}-\mathrm{S}-\mathrm{H}$. One can see however a broadening of these resonances when the fraction of TEOS decreases beyond $40 \%$.

Organosilicate species are also condensed into the form of chains because only $\mathrm{T}^{1}(\delta \sim-50 \mathrm{ppm})$ and $\mathrm{T}^{2}(\delta \sim-60 \mathrm{ppm})$ resonances are present. In the ethyl and aminopropyl series, the $T^{2} / T^{1}$ intensity ratio increases with the percentage of trialkoxysilanes. In these series, for samples containing a small fraction of organics (up to $40 \%$ ), the predominantly $\mathrm{T}^{1}$ environment for the trialkoxysilane species suggests either the formation of $\mathrm{T}^{1}-\mathrm{T}^{1}$ or $\mathrm{T}^{1}-\mathrm{Q}^{1}$ dimers or their incorporation at the end of the silicate chains $\left(\mathrm{T}^{1}-\mathrm{Q}^{2}\right)$. As the percentage of trialkoxysilanes increases, substitution of $\mathrm{Q}^{2}$ by $\mathrm{T}^{2}$ species occurs.

The behaviour of the $n$-butyl series is different because the shape of the $\mathrm{T}$ resonances does not evolve mainly with the butylsilane content $\$$. This may imply that a large part of the trialkoxysilanes is separated into a phase similar to the $100 \%$ end-series hybrid. This assertion is supported by XRD results which have shown that the basal distance value of the $100 \%$ substituted phase is seen all along the series. The differences between ethyl, aminopropyl, and butyl (or longer $n$-alkyl) series may be assigned to the difference of the organic group chemical affinity toward the inorganic framework. Whereas small amounts of ethylsilane and aminopropylsilane groups may be diluted inside the interlayer of $\mathrm{C}-\mathrm{S}-\mathrm{H}$ which is hydrophilic in essence, the butylsilane species would rather cluster together due to strong hydrophobic interaction of the butyl groups, hence leading to separation.

To confirm the incorporation of small organic groups in C-S-H via co-precipitation of TEOS and triethoxysilane in the presence of the calcium salt, CP-MAS ${ }^{29} \mathrm{Si}$ and $2 \mathrm{D}{ }^{1} \mathrm{H}-{ }^{29} \mathrm{Si}$ heteronuclear chemical shift correlation (HETCOR) experiments were performed on deuterated ethyl calcium silicate hybrids. In a first set of experiments, the materials were synthesized in $\mathrm{D}_{2} \mathrm{O}$ (without ethanol) using a $\mathrm{NaOD}$ solution to precipitate the hybrids which were then rinsed in $\mathrm{D}_{2} \mathrm{O}$. The ${ }^{1} \mathrm{H}$ NMR experiments confirmed that almost all protons come from organic groups linked to silanes. In particular, it was verified, using ${ }^{13} \mathrm{C} C \mathrm{CP}-\mathrm{MAS}$ NMR, that the alcohol formed by hydrolysis of the alkoxysilanes was eliminated during drying and that all alkoxy groups were hydrolyzed (see ESI $\dagger$ ). The CP-MAS ${ }^{29} \mathrm{Si}$ of the deuterated ethyl calcium silicate hybrids showed intense $\mathrm{Q}^{1}$ and $\mathrm{Q}^{2}$ peaks whereas these resonances were not detectable in deuterated pure inorganic $\mathrm{C}-\mathrm{S}-\mathrm{H}$ (Fig. 4). We can then argue that only the protons of the ethyl groups are responsible for the polarisation transfer. This result is a direct proof that ethyl groups are spatially close to silicate tetrahedra and confirms that organotrialkoxysilanes are incorporated into the silicate chains. For the HETCOR experiments, samples were deuterated by exchange in $\mathrm{D}_{2} \mathrm{O}$ for 3 weeks before drying in order to reduce the contribution of protons from residual water and silanols compared to protons from organic moieties. In the HETCOR spectrum of the $40 \%$ ethyl calcium silicate hybrid (Fig. 5), the ${ }^{1} \mathrm{H}$ projection consists of a main resonance at $1 \mathrm{ppm}$ due to ethyl groups as well as a small resonance at $\sim 5 \mathrm{ppm}$ due to water molecules and $\mathrm{Si}-\mathrm{OH}$. The $2 \mathrm{D}{ }^{1} \mathrm{H}$ slices clearly show that both $\mathrm{Q}^{1}$ and $\mathrm{Q}^{2}$

$\$$ Similar trends are observed with $n$-octylsilane, see ESI. $\dagger$ 


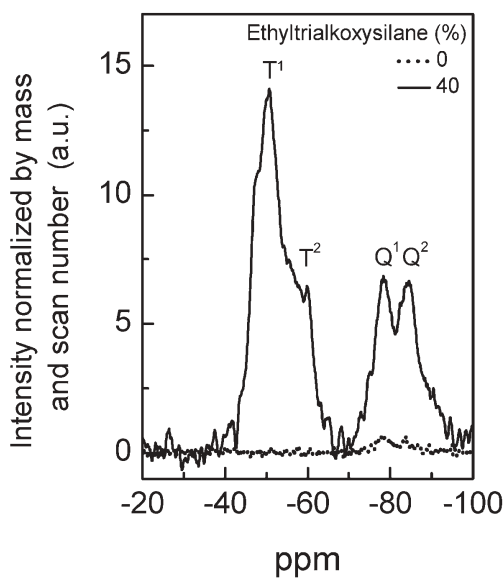

Fig. $4{ }^{29} \mathrm{Si}$ CP-MAS NMR spectra of deuterated samples made on $100 \%$ TEOS (pure $\mathrm{C}-\mathrm{S}-\mathrm{H}$ ) and made on a mixture of $40 \%$ ethyltriethoxysilane and 60\% TEOS. The intensities have been normalized by the sample mass and the scan number. The only proton source needed for polarization transfer came from ethyl groups linked to silicon atoms. The large $\mathrm{Q}^{1}$ and $\mathrm{Q}^{2}$ signals, only visible in the hybrid sample, are evidence of the homogeneous distribution of organic moieties in the $40 \%$ ethyl calcium silicate material.

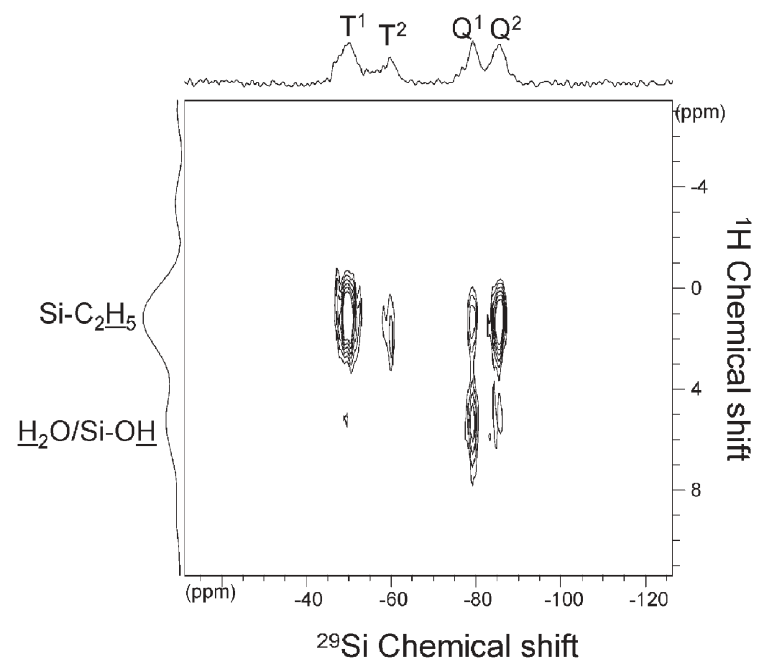

Fig. $52 \mathrm{D} \quad{ }^{1} \mathrm{H}^{-29} \mathrm{Si}$ heteronuclear chemical shift correlation (HETCOR) NMR experiments recorded for a sample containing $40 \%$ ethyltriethoxysilane and $60 \%$ TEOS. The ${ }^{1} \mathrm{H}$ MAS projection is shown along the vertical axis. This figure shows strong correlation peaks between protons of ethyl groups and Q species.

species are polarized by protons coming from ethyl groups. We can see that $\mathrm{T}$ species are slightly polarized by protons at $5 \mathrm{ppm}$ suggesting a poor environment of water and silanols around ethyl groups.

Both sets of NMR experiments $\left({ }^{29} \mathrm{Si}\right.$ CP-MAS and ${ }^{1} \mathrm{H}^{-29} \mathrm{Si}$ HETCOR) confirmed that organotrialkoxysilanes can be integrated in the silicate chains of $\mathrm{C}-\mathrm{S}-\mathrm{H}$ (identical conclusions have been obtained for aminopropyl calcium silicate hybrids, see ESI $\dagger$ ). From these results, it may be possible to make a schematic representation of the hybrids containing a small fraction of organics as shown in Fig. 6. In this figure, the parent layered structure of $\mathrm{C}-\mathrm{S}-\mathrm{H}$ is represented in agreement

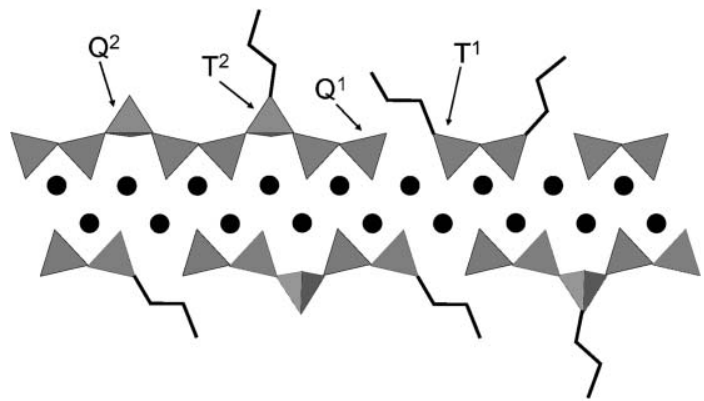

Fig. 6 Schematic model of a layer of hybrid calcium silicate materials showing the incorporation of organotriethoxysilane at the end and in the middle of $\mathrm{C}-\mathrm{S}-\mathrm{H}$ silicate chains. $(\bullet=$ calcium atoms $)$.

with XRD and the Q region of ${ }^{29} \mathrm{Si}$ NMR which shows the $\mathrm{C}-\mathrm{S}-\mathrm{H}$ structure integrity for hybrid materials containing less than $40 \%$ of ethyl or aminopropyl silanes. Some silicate tetrahedra $(\mathrm{Q}$ species) have been replaced by trialkoxysilane ( $\mathrm{T}$ species) leading to the incorporation of organic moieties in the interlayer.

\section{Conclusion}

In this work, we have shown that incorporating organic groups in calcium silicate hydrates $(\mathrm{C}-\mathrm{S}-\mathrm{H})$ can be achieved by coprecipitation of TEOS and trialkoxysilane with calcium salt in alkali media at room temperature without disrupting the inorganic framework. Whereas the present results have been obtained for very small organic groups, it seems however that phase separation occurred for larger-sized or for highly hydrophobic organic groups. This simple approach may offer new opportunities to design new cement based nanocomposites by covalently bonding monomer molecules into the interlayer of $\mathrm{C}-\mathrm{S}-\mathrm{H}$ and then proceeding to in-situ polymerisation. An alternative method currently under study consists of precipitating $\mathrm{C}-\mathrm{S}-\mathrm{H}$ in the presence of polymers containing trialkoxysilane functions in order to induce covalent bonding between the polymer and the silicate phases.

\section{References}

1 J. D. Birchall, A. J. Howard and K. Kendall, Nature, 1981, 289, 388.

2 O. O. Popoola, W. M. Kriven and J. F. Young, J. Am. Ceram. Soc., 1991, 74, 1928

3 B. L. Smith, T. E. Schaffer, M. Viani, J. B. Thompson, N. A. Frederick, J. Kindt, A. Belcher, G. D. Stucky, D. E. Morse and P. K. Hansma, Nature, 1999, 399, 761.

4 Z. Y. Tang, N. A. Kotov, S. Magonov and B. Ozturk, Nat. Mater., 2003, 2, 413

5 S. A. Hamid, Z. Kristristallogr., 1981, 154, 189.

6 H. F. W. Taylor, in Cement Chemistry, Thomas Telford, London, 2nd edn., 1997.

7 J. J. Chen, J. J. Thomas, H. F. W. Taylor and H. M. Jennings, Cem. Concr. Res., 2004, 34, 1499.

8 X. D. Cong and R. J. Kirkpatrick, Adv. Cem. Based Mater., 1996, 3, 133.

9 H. Matsuyuma and J. F. Young, J. Mater. Res., 1999, 14, 3379.

10 H. Matsuyama and J. F. Young, J. Mater. Res., 1999, 14, 3389.

11 H. Matsuyama and J. F. Young, Chem. Mater., 1999, 11, 16.

12 A. Popova, G. Geoffroy, M. F. Renou-Gonnord, P. Faucon and E. Gartner, J. Am. Ceram. Soc., 2000, 83, 2556. 
13 F. Merlin, H. Lombois, S. Joly, N. Lequeux, J. L. Halary and H. Van Damme, J. Mater. Chem., 2002, 12, 3308.

14 M. Evain, P. Deniard, A. Jouanneaux and R. Brec, J. Appl. Crystallogr., 1993, 26, 563.

15 X. D. Cong and R. J. Kirkpatrick, Adv. Cem. Based Mater., 1996, 3, 144.
16 J. Minet, S. Abramson, B. Bresson, C. Sanchez, V. Montouillout and N. Lequeux, Chem. Mater., 2004, 16, 3955.

17 G. Engelhardt, H. Jancke, M. Mägi, T. Pehk and E. Lippmaa, J. Organomet. Chem., 1971, 28, 293.

18 G. Engelhardt, M. Mägi and E. Lippmaa, J. Organomet. Chem., 1973, 54, 115. 